\title{
O suplemento como mapa da vida cultural: análise do caderno Cultura (2010) de Zero Hora ${ }^{1}$
}

\author{
SARA KELLER \\ UFRGS - E-mail: sara keller25@hotmail.com \\ Mestre em Comunicação e Informação pelo PPGCOM/UFRGS
}

Cassilda Golin Costa

UFRGS - E-mail: cidago@terra.com.br Professora do PPGCOM/UFRGS na linha Jornalismo e Processos Editoriais

\begin{abstract}
Resumo
O caderno semanal Cultura, do jornal Zero Hora, é hoje a única publicação jornalística no Rio Grande do Sul que assume o papel de aglutinar intelectuais e acadêmicos, mediando campos especializados para um público mais amplo. Considerando que o jornalismo institui valores e documenta tendências de uma época, e que o suplemento é um espaço que concentraria os temas mais relevantes, este artigo busca compreender como o caderno enquadrou a vida cultural local em 2010. Utilizou-se análise de conteúdo nas 52 edições publicadas no ano. Observou-se que o caderno estrutura-se a partir de valores caros ao campo jornalístico como atualidade, notoriedade e proximidade. Privilegia manifestações artísticas reconhecidas, segue a lógica de consumo e tem no editor uma figura central. Verifica-se no caderno o protagonismo de instâncias como o saber acadêmico, a crítica, a notoriedade dos criadores e dos agentes especializados.
\end{abstract}

Palavras-chave

Jornalismo cultural; suplemento cultural; cultura; caderno Cultura; Zero Hora.

1 Artigo reestruturado a partir de paper homônimo apresentado no $10{ }^{\circ}$ Encontro Nacional de Pesquisadores em Jornalismo, em 2012. 


\begin{abstract}
Zero Hora's weekly supplement Cultura is today the only journalistic publication in Rio Grande do Sul that assumes the role of agglutinate intellectuals and academics, approaching specialized fields and a wider audience. Considering that journalism can establish values and register tendencies of a certain time, and also that supplements supposedly concentrate the most important facts of the cultural field, this article seeks to understand how Cultura represented the cultural life in 2010. Content Analysis was used with a corpus of the 52 issues published that year. The results indicate the supplement is structured based in present time, notoriety and proximity. It privileges the traditional artistic expressions, follows the consumption's logic and has in its editor a central figure. It can be verified the prominence of instances like the academic knowledge, critics, creator's notoriety and specialized agent's notoriety.
\end{abstract}

\title{
Keywords
}

cultural journalism; cultural supplement; culture; Cultura supplement; Zero Hora.

Artigo recebido em 01/06/2013

Aprovado em 19/06/2013 


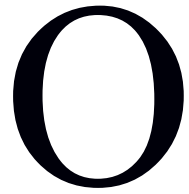

s suplementos semanais são publicações referenciais na história do jornalismo cultural. Eles fornecem um indicativo do pensamento e dos valores de uma época, hierarquizando, em um espaço restrito, temas culturais significativos. Foi em abril de 1967, quando a maioria dos grandes jornais brasileiros já mantinha cadernos do gênero que, em Porto Alegre, no Rio Grande do Sul, Zero Hora lançou seu Caderno de Cultura, ainda na primeira fase do periódico. A publicação nasceu uma década depois dos paradigmáticos suplementos literários nacionais, mas cinco meses antes de seu contemporâneo prestigioso, o Caderno de Sábado (1967-1981) do Correio do Povo, na época o principal jornal do estado.

O Caderno de Cultura, com direção editorial de Marcos Faerman e Sidney Schestaskie supervisão do crítico literário e professor Guilhermino César, foi o embrião do que viria a ser o suplemento Cultura que conhecemos atualmente, encartado aos sábados no veículo de maior circulação paga no Rio Grande do $\mathrm{Sul}^{2}$, remanescente local da chamada tradição histórica dos suplementos culturais. Após diversas reformulações, o caderno configura-se hoje como o único formato jornalístico que assume o papel de aglutinar intelectuais e acadêmicos, mediando campos especializados para um público mais heterogêneo. Sua singularidade é, no mínimo, curiosa, uma vez que Porto Alegre conheceu um passado editorial de experiências múltiplas e marcantes na área da cultura.

Este artigo, resultante de dissertação defendida em 2012 no Programa de PósGraduação em Comunicação e Informação da Universidade Federal do Rio Grande do Sul (PPGCOM/UFRGS), pretende discutir como o caderno Cultura expressa parâmetros de compreensão da vida cultural local. Partiu-se do entendimento de que o jornalismo tem o poder de instituir valores, reforçar consensos e registrar tendências, e que o suplemento semanal é um espaço que foge à lógica diária de cobertura, supostamente concentrando o que de mais significativo acontece na área. A análise de conteúdo (BARDIN, 1977) foi aplicada nas 52 edições de 2010, resultando em 422 textos indexados. Além disso, uma entrevista em profundidade (DUARTE, 2009)

2 Zero Hora é, hoje, o principal jornal do conglomerado de mídia RBS (Rede Brasil Sul de Comunicação) e o maior em circulação no RS. Em 2011, foi o sexto maior jornal em circulação paga no Brasil, segundo a Associação Nacional de Jornais (ANJ), com média de circulação de 188.561 exemplares. 
realizada com o editor Luiz Antônio Araujo $^{3}$, responsável pela publicação naquele período, complementou os resultados.

\section{Os suplementos culturais no contexto da hiperescolba}

Os suplementos dos anos 1950 - época áurea do gênero, quando foram lançados o Suplemento Literário de O Estado de São Paulo e o Suplemento Dominical do Jornal do Brasil -, constituíam verdadeiras redes de sociabilidade. Junto com outras instâncias, permitiam a estruturação do campo cultural, refletindo alianças, antagonismos, influências, além do encontro de gerações de críticos e pensadores (ABREU, 1996). Em mais de meio século de resistência, entre o nascimento e a morte de tantos títulos, os cadernos perderam parte de suas características iniciais, como a ênfase na publicação de fragmentos literários, por exemplo. Suas edições, no entanto, constituem indícios do microcosmo intelectual e oferecem um instantâneo do que é ser culto em determinada época. Transparece, ali, a rotina de tensão entre a edição jornalística e a palavra de determinados especialistas convocados a usufruir da visibilidade midiática e, ao mesmo tempo, conferir prestígio ao jornal que os acolhe.

Nesse jogo pelo prestígio, atua um segmento de leitores para quem a leitura dessas publicações seria um hábito distintivo, dispositivo para o aperfeiçoamento da formação intelectual. É comum, inclusive, o estabelecimento de um forte laço de fidelidade: leitores costumam colecionar suplementos culturais, repercutindo o amplo horizonte de seu conteúdo e recepção.

Em um mercado de múltiplas ofertas como é o da cultura, o fluxo constante de mercadorias tornaria ainda mais importante o gosto, o julgamento e o capital cultural acumulado por indivíduos ou grupos. Dessa forma, os suplementos funcionam como mecanismos de hierarquização de temas, obras, artistas e produtos. Em meio ao contexto da chamada hiperescolha (LIPOVETSKY; SERROY, 2011), eles dão ordem ao caos de uma oferta abundante, destacando o que deve ser conhecido e consumido em meio a tantas possibilidades. Na função de selecionar, o suplemento indica ao leitor $3 \mathrm{Em} Z$ H, foi repórter especial com passagens nas editorias de Capa, Geral, Digital e Política. Em 2012, assumiu a editoria de Internacional e passou a edição do suplemento para a jornalista Sandra Simon. 
determinado mapa de aprendizado e competência cultural. Esse caminho hoje está atrelado, também, ao poder de compra, o que pode ser verificado com a constante submissão de tais publicações à lógica mercantil e ao ritmo dos lançamentos.

\section{A cultura nas páginas de Zero Hora}

Em visitas ao Centro de Documentação e Informação da RBS e ao arquivo do Museu da Comunicação Hipólito José da Costa, ambos em Porto Alegre, foi possível retomar marcos da cronologia do suplemento Cultura enquanto empreendimento editorial. Percurso necessário para entender sua versão contemporânea, que até o momento não havia sido compilado historicamente. Em 13 de abril de 1967 nascia o Caderno de Cultura de Zero Hora, com o intuito de reunir expoentes no cenário cultural gaúcho, mesmo que, naquele momento, o jornal não ostentasse a representatividade econômica e de público que possui hoje. O primeiro número da edição quinzenal reuniu, entre os autores de artigos opinativos, o escritor Erico Verissimo, o jornalista Pilla Vares e o crítico Guilhermino César. O apelo à relação de fidelidade com o leitor pode ser percebido em uma chamada publicada na capa do jornal de 11 de abril de 1967, dois dias antes da estreia, convidando o público a colecionar o novo encarte.

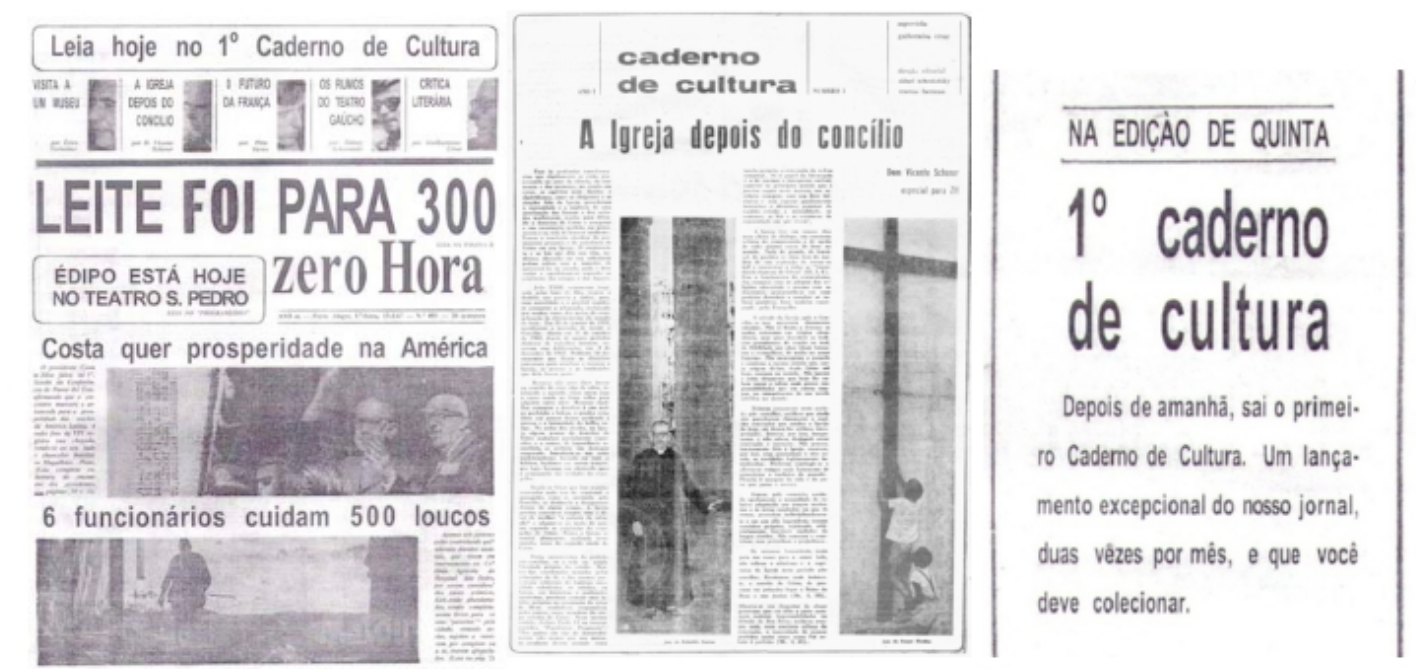

Figura 1 - Capa de 13/04/1967 trazia chamada para o primeiro Caderno de Cultura (à esquerda). Capa da primeira edição do suplemento (centro). Chamada na capa de 11/04/1967 indicava a intenção de ser colecionável (à direita). 
O Caderno de Cultura de ZH, com esta denominação, continuou até 1970. A edição de número 60, de 11 de abril, fechou esse primeiro ciclo. Haveria, então, um hiato de onze anos até que outra publicação com as mesmas características voltasse ao jornal. Nesse intervalo, Zero Hora continuava publicando, diariamente, páginas dedicadas à cultura, ao roteiro e às variedades. No fim de semana circulavam encartes como o Guia, que saía aos sábados com matérias, programação cultural, de lazer e passatempos; a Revista $Z H$, extensa e com uma pauta eclética que abrangia temas femininos; e o Caderno $D$, dominical, com reportagens e textos variados.

Somente no início dos anos 1980, apareceria um suplemento mensal para preencher a lacuna deixada por seu antecessor. Em 03 de outubro de 1981 foi lançado o primeiro ZH Cultura. O texto de apresentação, ratificado em editorial, destacava o perfil reflexivo, reunindo textos sobre artes, literatura e ciências humanas. É interessante notar que o ZH Cultura, previsto para circular no primeiro sábado de cada mês, nascia com a promessa de não ser "fechado e elitista", como outros suplementos. A afirmação talvez tenha sido uma alusão ao próprio Caderno de Sábado (Correio do Povo), que encerrava sua trajetória no início de 1981, e que ficou conhecido por seu caráter sofisticado e enciclopédico (CARDOSO, 2009). O primeiro número do ZH Cultura trazia na capa os cem anos de nascimento do pintor espanhol Pablo Picasso.

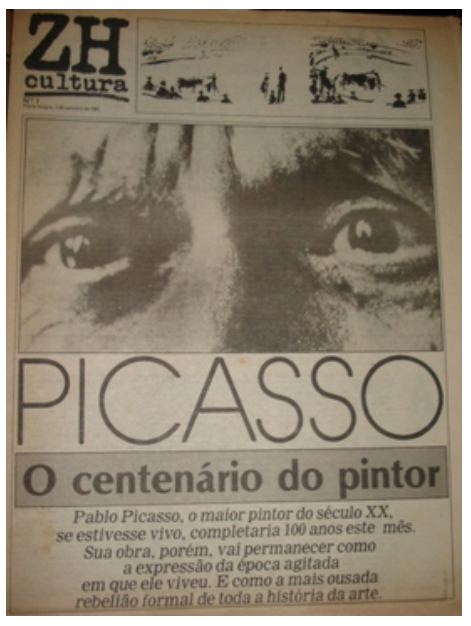

Figura 2 - Capa da primeira edição do ZH Cultura, de 03/10/1981.

O ZH Cultura circulou até 1991. No ano seguinte, 1992, quando Zero Hora 
buscava visibilidade e abrangência nacional, vários ajustes editoriais foram implementados (FONSECA, 2008). Surgiu, então, o Cultura, como parte integrante do Segundo Caderno (caderno cultural diário de $Z H$, que nomeia a editoria de cultura) e com uma alteração muito significativa: passou a ser publicado semanalmente. Quase uma década depois, em 1998, o cenário já era outro e o jornal apostava naquilo que até hoje o distingue como produto: o hiperlocalismo como marca discursiva que determina a hierarquia das pautas, configurando uma comunidade imaginada de leitores interpelados por aspectos identitários e de pertencimento a uma região (FELIPPI, 2006).

Independentemente da alternância de editores, que imprime características particulares a cada período de edição, linhas mestras conduzem a publicação desde seus primórdios: a ênfase na proximidade e no local, pilares da concepção editorial e mercadológica do jornal, privilegiando acontecimentos da região de cobertura ou que tenham alguma relação com o Rio Grande do Sul. Nessa construção, Porto Alegre assume o lugar referencial de cidade sede, de Capital no mapa físico e imaginado construído nas rotinas produtivas. Permanece a intenção de contemplar temas abrangentes e servir como fórum para aproximar o repertório especializado de um público supostamente mais amplo. Conforme reiterado nos editoriais, a publicação busca leitores fora do campo acadêmico, embora seja constituída majoritariamente por colaboradores oriundos dessa área. Por fim, o suplemento assume-se como espaço principal de mediação de saberes no contexto da imprensa diária do Rio Grande do Sul. Em 1998, uma reforma gráfica redesenhou o suplemento e o colocou no formato que vigorou até 2010, ano em que se concentrou a dissertação ${ }^{4}$.

\section{Perspectiva temática do caderno}

$\mathrm{Na}$ análise das 52 edições do Cultura publicadas em 2010, buscamos identificar os principais parâmetros da movimentação cultural propostos pelo caderno,

4 A publicação em 2010 apresentava oito páginas coloridas, com quatro colunistas fixos: o músico e professor Celso Loureiro Chaves (música); o professor Claudio Moreno (língua portuguesa); o fotógrafo Ricardo Chaves (fotografia); e o escritor e professor Luís Augusto Fischer (temas variados, com ênfase na literatura). 
veiculado em um jornal hegemônico como Zero Hora. Visando compor uma panorâmica do perfil editorial do suplemento e entender de que forma ele enquadra jornalisticamente o sistema de cultura, determinamos as seguintes categorias para analisar em cada um dos 422 textos do corpus: tema, autoria, gênero, referência geográfica, referência temporal, valores-notícias e gancho jornalístico. A seguir, apresentaremos os resultados combinados dessas categorias, identificando aquilo que o Cultura repete e enfatiza na leitura do campo artístico e intelectual.

No período analisado, o caderno apresentou extenso escopo temático, da política à psicanálise, passando pelo jornalismo e pelo esporte, entre vários outros assuntos, muitos deles ligados às Humanidades. Em termos quantitativos ${ }^{5}$, os temas mais recorrentes foram Literatura e livros, Música e História, respectivamente, aproximando o encarte de uma perspectiva comum ao jornalismo cultural, que prioriza manifestações artísticas reconhecidas.

A ênfase na literatura e no mercado editorial sintoniza o caderno à tradição dos suplementos em geral, que sempre concederam protagonismo ao setor. A amostra privilegiou o clássico, o cânone internacional, especialmente escritores notórios sobre os quais a publicação pretende informar, trazendo diferentes aspectos sobre suas vidas e obras. Como exemplo, houve duas edições dedicadas a dois prêmios Nobel. A primeira, em 19 de junho, foi exclusiva sobre o português José Saramago, por ocasião de sua morte. A segunda foi publicada em 09 de outubro, dois dias após o escritor peruano Mario Vargas Llosa ganhar o prêmio Nobel de 2010. Llosa passaria por Porto Alegre para fazer uma conferência no evento Fronteiras do Pensamento.

Já a presença significativa da música se deve, em boa parte, à coluna quinzenal de Celso Loureiro Chaves, dedicada, predominantemente, ao gênero erudito, tema recorrente também em outros textos. Um espaço quinzenal que se alterna com a música (a coluna sobre língua portuguesa O Prazer das Palavras, de Claudio Moreno) enfatiza

5 Ao todo foram identificadas 19 temáticas principais. São elas: Literatura e livros (31\%); Música (10\%); História (9\%); Língua portuguesa (5\%); Artes plásticas (5\%); Política (4\%); Cinema (3\%); Fotografia (3\%); Política Cultural (3\%); Identidade Regional (3\%); Pensamento (2\%); Filosofia (2\%); Jornalismo (2\%); Psicanálise (2\%); Educação (2\%); Relações Internacionais (1\%); Artes Cênicas (1\%); Ecologia e Ambientalismo (1\%); e Outros (11\%). Em Outros estão reunidas as demais categorias, que tiveram cinco ocorrências ou menos no caderno no período analisado. 
a importância de se conhecer o saber legitimado, abordando questões relativas à linguagem culta.

Ao mesmo tempo em que reafirma as artes e o cânone, o caderno Cultura investe na História, dando a este segmento um relevo expressivo. Entre as páginas selecionadas, citamos como exemplo uma edição especial sobre a Revolução de 1930, marcando os 80 anos do levante, ou mesmo o episódio sobre os casos de amor entre soldados brasileiros e mulheres paraguaias durante a Guerra do Paraguai (1864-1870), a partir de uma dissertação de mestrado realizada na Unisinos, RS. O investimento em textos baseados na contextualização e no resgate histórico, mesmo na proporção máxima de 70 linhas, demonstra a intenção formativa típica dos suplementos culturais.

Por outro lado, a definição e o tratamento dados a cada recorte temático relacionam-se diretamente à forma como o jornalismo interpreta o sistema cultural sob os valores caros ao seu próprio campo. Seguindo a classificação dos valores-notícia substantivos de seleção, proposta por Nelson Traquina $(2008)^{6}$, notamos que o caderno estrutura-se a partir de três critérios principais: a atualidade dos fatos; a notoriedade dos sujeitos; e a proximidade, física ou cultural, dos acontecimentos para com o públicoalvo $^{7}$.

\section{A cartografia do sistema de cultura ancorada na atualidade}

A análise mostrou que, embora circule aos sábados e, portanto, usufrua de uma temporalidade mais estendida, o Cultura privilegia a atualidade e a novidade, mesmo que a perspectiva de muitos textos esteja baseada no passado ou na memória. Muitos dos ganchos que justificam cada escolha - lançamentos e eventos, efeméride, polêmica,

6Dentro da proposta do autor (TRAQUINA, 2008), optamos pelos critérios substantivos de seleção, que apontam as características intrínsecas ao fato. São eles: morte; notoriedade; proximidade; tempo (novidade/atualidade, efeméride, continuidade); notabilidade; relevância; inesperado; conflito ou controvérsia; e infração, valor ligado ao escândalo.

7 Ao estudar os valores-notícias presentes nos textos do caderno Cultura em 2010, seguindo a classificação de Traquina (2008), obtivemos os seguintes resultados (em número de ocorrências): Temponovidade (310); Notoriedade (289); Proximidade (172); Conflito ou controvérsia (40); Tempo-efeméride (39); Morte (24); Relevância (14); Tempo-continuidade (13); Notabilidade (10); Infração (8); Inesperado (8). 
morte, acontecimentos jornalísticos fora do campo cultural ou mesmo a demanda de leitores - estão situados no presente. A já citada edição sobre José Saramago foi exemplar, segundo o editor Luiz Antônio Araujo, da condição de que a publicação responde às questões do dia: “[...] O Saramago morreu de madrugada, eu fiquei sabendo disso na sexta por volta das $9 \mathrm{~h}$ e o caderno, às $12 \mathrm{~h} 30$, baixou uma edição totalmente virada, como a gente diz, focada no seu legado." (ARAUJO, 2012).

A âncora na atualidade aponta também para o quanto o caderno baseia sua pauta nos lançamentos, reforçando a importância da divulgação dos bens culturais e da distinção que proporcionam. Ao funcionar como um crivo de seleção no ritmo frenético e contínuo do mercado, ele enfatiza a centralidade do consumo no cotidiano da cultura, como a maioria dos encartes culturais, diários ou não.

Já a projeção sobre o futuro foi encontrada nos textos em quantidade bem inferior se comparada às indicações do presente ou passado. Ou seja, a principal preocupação do suplemento não é prospectar ou antecipar tendências, e sim fazer um registro de seu próprio tempo. Nesse âmbito, durante o período analisado, também não houve um realce maior para o mapeamento de novos agentes, obras emergentes ou pouco reconhecidas no seu campo, mas para a reafirmação do canônico.

\section{A notoriedade}

A notoriedade dos sujeitos foi, portanto, um aspecto central da cobertura, confirmando a inclinação genérica do jornalismo em afiançar artistas e obras já consolidados no mercado e no campo cultural, garantindo-lhes ainda mais prestígio. $\mathrm{Na}$ escolha da resenha de um livro recém-lançado, por exemplo, a reputação do escritor pode influir de modo decisivo. O lançamento no Brasil do novo romance do Nobel J. M. Coetzee dificilmente não seria pauta, pela relevância do autor no cenário literário internacional. Da mesma forma, o livro de memórias de infância de Ana Luisa Escorel, filha dos intelectuais Antonio Candido e Gilda de Mello e Souza, teria grandes chances de ser escolhido. 
A morte, valor-notícia fundamental dos jornalistas (TRAQUINA, 2008), também está apoiada na celebridade de quem morreu. Ao registrá-la, o jornalismo enfatiza narrativamente a vida, algo que na editoria de cultura assume o contorno de testamento, revisão de herança simbólica e garantia de legitimidade para o futuro. Em 2010, o Cultura registrou as mortes do diretor francês Eric Rohmer, do escritor norteamericano J. D. Salinger, do crítico literário Wilson Martins, entre outras.

Outro aspecto da notoriedade é que ela aparece vinculada aos indivíduos que escrevem textos na condição de colaboradores, fixos ou eventuais. Foram encontrados 155 autores diferentes entre os 319 textos assinados. De forma geral, os autores são, em ordem de frequência, colunistas, jornalistas de $Z H$, professores universitários e profissionais da área cultural, pessoas com reconhecimento em sua área de atuação.

No caso dos colaboradores ligados às universidades, são nomes que representam o saber legitimado e que encontram no suplemento um meio de exposição. A maioria é oriunda da Universidade Federal do Rio Grande do Sul, concedendo a essa instituição o papel notório de autoridade científica ${ }^{8}$. Os agentes culturais constituem outro grupo significativo. São escritores, diretores, produtores, críticos e até políticos, entre outras ocupações relevantes no sistema de produção e distribuição da cultura.

Logo, ao tentar montar um mapa do sistema cultural, verificando quem escreve no caderno de $Z H$, percebemos que, quantitativamente, as áreas mais realçadas foram justamente o campo literário (escritores e agentes desse segmento); a instância crítica (autores identificados como críticos de diferentes áreas); e os profissionais da música. Em menor escala estão atividades ligadas às artes plásticas, artes cênicas e ao cinema. Encontramos ainda um número relevante de psicanalistas, refletindo a força das correntes do pensamento psicanalítico em Porto Alegre.

Nesse sentido, é possível dizer que a questão da autoria é bastante valorizada pela publicação de $Z H$. Percebe-se isso especialmente na apresentação que identifica cada colaborador, frisando suas obras. De modo geral, é comum a repetição de nomes locais. Apesar de termos encontrado, em menor grau, articulistas nacionais e

8 Em 2010, três dos quatro colunistas fixos possuíam estreito vínculo com a UFRGS, tendo ali construído boa parte de sua trajetória profissional. 
internacionais, há dificuldade em apresentar vozes para além do circuito próximo. Enquanto silencia sobre um número muito maior de autores e discussões, o suplemento enfatiza o protagonismo dos sujeitos a quem confere visibilidade, valor já afiançado pelo próprio campo cultural, pelo mercado ou pelo campo científico.

\section{Tensão entre o local e o forâneo}

Como vimos, outro valor-notícia prioritário para a publicação é a proximidade dos temas, seja ela cultural ou geográfica, com o Rio Grande do Sul. No caso de Zero Hora, mesmo quando um fato não está fisicamente ligado ao estado, o jornal busca relacioná-lo de alguma forma a uma perspectiva regional. O suplemento não foge à regra, relacionando suas pautas, sempre que pode, ao contexto em que está inserido.

O apelo hiperlocalista de $Z H$, por outro lado, faz do caderno um espaço de constante tensão entre assuntos locais e externos. Entre as referências espaciais detectadas nos textos, a predominância foi, curiosamente, dos temas forâneos, envolvendo agentes, acontecimentos e obras internacionais, embora o gancho para muitos desses textos esteja situado no local. É importante considerar que grande parte dos colaboradores, mesmo que não esteja vinculada à redação e ao conceito editorial do jornal, tem origem regional e escreve a partir dessa condição. Assim, o Cultura refrata um olhar constituído majoritariamente a partir do Rio Grande do Sul.

Devemos lembrar que boa parte do teor internacional, ou mesmo do prestígio do pensamento contemporâneo presente no suplemento, deve-se à cobertura sistemática do ciclo de palestras Fronteiras do Pensamento, que ganhou patrocínio da $R B S$ em $2010^{9}$ e que trouxe personalidades de diversas áreas a Porto Alegre. Foi o caso do neurocientista Miguel Nicolelis e do cientista social e economista Eduardo Gianetti, que concederam entrevistas; do crítico britânico Terry Eagleton e do historiador italiano

9 A RBS é uma das patrocinadoras do evento desde 2010. Muitas das ações do grupo no cenário da cultura (realizações próprias ou apoios) pautam seus veículos. No caderno Cultura, isso é evidente: eventos, como o prêmio Fato Literário (destinado a personalidades e iniciativas de destaque no cenário local), o projeto Histórias Curtas (que financia filmes curtas-metragens, depois exibidos pela RBS TV) e o ciclo de palestras Fronteiras do Pensamento, são pautas recorrentes. 
Carlos Ginzburg, que assinaram textos. Paradoxalmente ao acento na perspectiva regional, a movimentação proporcionada pelo Fronteiras e retratada de forma intensa concede a Porto Alegre a perspectiva dinâmica de um espaço mais cosmopolita, de circulação de expoentes e fluxos culturais externos, de agitação intelectual, onde se debatem temas que afligem o setor.

\section{Conflito e polêmica}

Historicamente, os suplementos semanais se constituíram em fóruns de polêmicas e discussões do campo cultural. Em nossa amostra, percebemos que alguns temas tratados em 2010 foram abordados sob a perspectiva da polêmica e do conflito, geralmente por meio do debate gerado pela repercussão de um artigo, sua réplica ou tréplica. As polêmicas, quando existiram, evocaram o contexto local, que vivia o último ano do mandato da então secretária estadual da Cultura Mônica Leal. As discussões sobre política cultural apontavam para uma crise no setor, com o fechamento da Sala de Cinema Norberto Lubisco, na Casa de Cultura Mario Quintana, em Porto Alegre, e com a demissão do historiador Voltaire Schilling da direção do Memorial do Rio Grande do Sul; outras indicavam as expectativas sobre o novo titular da Secretaria de Cultura. Muito se discutiu, naquele momento, a respeito da nova sede da Orquestra Sinfônica de Porto Alegre (Ospa), que completou 60 anos em 2010. Mesmo sendo a segunda orquestra mais antiga em atividade ininterrupta no Brasil e tendo sempre desenvolvido um trabalho sistemático na disseminação da música clássica, a Ospa até então não possuía sede própria, fato que levou personalidades do sistema cultural local a se manifestar em seu favor.

\section{Julgamento e hierarquização: a mediação do editor}

A análise do caderno Cultura permitiu observar que os textos opinativos são 
predominantes em suas páginas. Ensaios, artigos e comentários foram os gêneros mais recorrentes, seguidos por colunas, críticas e resenhas. O Cultura, portanto, mesmo apresentando gêneros informativos, coloca-se como um espaço reflexivo ligado à opinião. Desse modo, acompanha o perfil de publicações similares quanto ao estímulo ao pensamento e à troca de ideias, colocando-se como dispositivo para o aperfeiçoamento intelectual, à medida que o leitor teria em mãos um veículo com textos mais aprofundados do que os encontrados no jornalismo diário. Como resumiu Bentancur, os suplementos tentam "criar, dentro dos templos erigidos à memória do passageiro, algo de permanente" (2000, p.10).

A opinião nos textos, porém, sofre um processo de adaptação centralizado na figura do editor, elemento primordial na confecção de um gênero como o Cultura, no qual essa função, assim como a dos colunistas, é praticamente a única fixa. O editor assume papel fundamental na garantia de legibilidade. Ele faz boa parte da intermediação entre os discursos de especialistas dos mais variados campos e o leitor comum, iniciado ou não nos assuntos tratados. Essa rotina, segundo Luiz Antônio Araujo (2012), implica muitas vezes na recusa de textos ou na solicitação de reescrita de um artigo. Na medida em que possui certa autonomia para escolher os assuntos entre tantas ofertas, é a figura do editor, com toda a subjetividade implícita, que personaliza e define o que o caderno mostrará para o futuro, considerando a condição do jornalismo de documentar a movimentação cultural.

\section{Considerações finais}

Como parte de um jornal de grande circulação, o Cultura propõe um quadro parcial de leitura do sistema cultural, contingência da própria prática jornalística, marcada pela necessidade de exclusão e julgamento no espaço fisicamente limitado. Nesse processo de hierarquização, o suplemento estudado apoia-se em critérios naturalizados pelo campo jornalístico - atualidade, notoriedade e proximidade - para conceder visibilidade a determinadas instâncias e atores hegemônicos do campo 
cultural.

Em tal recorte, podemos dizer que algumas instituições e sujeitos foram privilegiados. Em 2010, passaram pelas páginas do caderno especialmente aqueles que representam a pesquisa e o saber acadêmico, a crítica e a criação. Acompanhamos ainda a recorrência de instâncias consagradoras, dos locais de exposição e dos agentes especializados.

A partir de tais constatações, percebemos que ao montar o mapa que ajudará o leitor a interpretar a cultura de seu tempo, o suplemento propõe um quadro que privilegia especialmente o conhecimento produzido na universidade, visto que professores e estudantes de pós-graduação compõem uma parcela significativa dos colaboradores. Promove, assim, uma aproximação com valores do campo acadêmico, espaço de disputas como qualquer outro, no qual os agentes estão em busca de visibilidade, do reconhecimento de sua autoridade e da validação do seu discurso.

Seguindo a função histórica de esclarecimento que os suplementos carregam consigo, o Cultura assume a função de mediador, visando, supostamente, aproximar os saberes especializados de um público mais amplo e menos específico. O caderno segue a tendência de publicações congêneres ao valorizar as artes, a literatura, a música e a norma culta. Ao mesmo tempo, sua abrangência é extensa, sugerindo como indicativo de cultura o conhecimento eclético, a análise e a opinião. Mais do que saber muito sobre determinado assunto, a noção de cultura do suplemento de $Z H$ implica conhecer um pouco sobre diversos aspectos relacionados ao campo cultural e, principalmente, acompanhar a oferta de produtos disponíveis para consumo. Ainda que explicite a tensão entre o forâneo e o local, o caderno assume sua condição de intermediário do sistema cultural, ancorado na produção intelectual regional e nas fronteiras do projeto mercadológico da organização em que está inserido.

Essa foi uma primeira panorâmica sobre as características do suplemento. A dissertação da qual este artigo é resultante foi o primeiro estudo acadêmico dedicado a sistematizar o perfil do Cultura e motivou o início de uma nova pesquisa ${ }^{10}$, desta vez

10 Jornalismo e sistema cultural: estudo da representação da cidade no suplemento Cultura de Zero Hora, desenvolvida no PPGCOM a partir de 2012, com recursos do CNPq e UFRGS. 
contemplando a análise de 208 números do suplemento publicados entre 2006 e 2009. Somando os resultados de 2010, será possível visualizar as diferentes fases do caderno em uma perspectiva de cinco anos. Nesse próximo mapeamento, a investigação objetiva problematizar a representação da cidade, entendida como espaço de capital simbólico e criativo e, portanto, agente central do sistema de cultura. Acreditamos que o perfil editorial desse caderno, como leitor da cultura contemporânea, poderá ser esmiuçado e aprofundado no decorrer dessa próxima pesquisa, assim como sua contribuição para a história do jornalismo. 


\section{Referências Bibliográficas}

ABREU, A. A.. Os suplementos literários: os intelectuais e a imprensa nos anos 50. In:

et al. (Org.) A imprensa em transição: o jornalismo brasileiro nos anos 50. RJ: Ed. Fundação Getúlio Vargas, 1996.

ARAUJO, L. A.. Entrevista concedida a Sara Keller. Porto Alegre, 6 jan. 2012.

BARDIN, L. Análise de conteúdo. Lisboa: Edições 70, 1977.

BENTANCUR, P. Ascensão e queda dos suplementos culturais. Revista Vox. Porto Alegre, n.0, p.5-11, out. 2000.

CARDOSO, E. Enciclopédia para formar leitores: a cultura na gênese do Caderno de Sábado do Correio do Povo (Porto Alegre, 1967-1969). 2009. Dissertação (Mestrado em Comunicação e Informação) - Programa de Pós-Graduação em Comunicação e Informação, Universidade Federal do Rio Grande do Sul. Porto Alegre, 2009.

DUARTE, J. Entrevista em profundidade. In: pesquisa em comunicação. São Paulo: Atlas, 2009. p.62-83.

; BARROS, Antonio (Org). Métodos e técnicas de

FELIPPI, A. Jornalismo e identidade cultural: construção da identidade gaúcha em Zero Hora. 2006. Tese. (Doutorado em Comunicação Social) - Curso de Pós-Graduação em Comunicação Social, Pontifícia Universidade Católica do Rio Grande do Sul. Porto Alegre, 2006.

FONSECA, V. Indústria de Notícias: capitalismo e novas tecnologias no jornalismo contemporâneo. Porto Alegre: Editora da UFRGS, 2008.

LIPOVETSKY, G.; SERROY, J. A cultura-mundo: resposta a uma sociedade desorientada. São Paulo: Companhia das Letras, 2011.

TRAQUINA, N. Teorias do Jornalismo: a tribo jornalística - uma comunidade interpretativa transnacional. $2^{\mathrm{a}}$ Ed. Florianópolis: Insular, 2008. V.2.

Este artigo e todo o conteúdo da Estudos em Jornalismo e Mídia estão disponíveis em http://www.periodicos.ufsc.br/index.php/jornalismo/index

Estudos em Jornalismo e Mídia está sob a Licença Creative Commons 